zeigten bei $100^{\circ} \mathrm{C}$. nie eine Gewichtsabnahme, die auf eine Beimengung eines krystallwasserhaltigen Körpers hätte schliessen lassen. Gemische aus Pikrotoxinin und Pikrotin (zuvor ans Wasser umkrystallisirt) verloren bei $100^{\circ} \mathrm{C}$. meist wechselnde Mengen von Krystallwasser; nur in einigen wenigen Fällen konnte auch hier eine Gewichtsabnahme nicht constatirt werden.

4) Das Verhalten des Pikrotoxins gegen Benzol und gegen Chloroform (s. dort).

\title{
II. Ueber das Cocculin.
}

Von Emil Löwonhardt.

Bei der Darstellung des Pikrotoxins nach dem in der vorstehenden Abhandlung beschriebenen Verfahren erhielt ich eine geringe Menge einer Verbindung, welche sich sowohl in ihrem Aeusseren, als auch in dem Verhalten gegen Lösungsmittel und gegen Agentien wesentlich von dem Pikrotoxin unterschied. Durch wiederholtes Ausziehen mit absolutem Alkohol liess sich dieser Körper leicht von Pikrotoxin und durch Umkrystallisiren aus heissem, salzsäurehaltigem Wasser von anorganischen Beimengungen befreien. Die derartig gereinigte Verbindung bildet feine, weisse Nadeln, die nur schwer in heissem Wasser, nahezu unlöslich in kaltem Wasser, Alkohol und Aether sind. Die bei den Analysen dieses Körpers ermittelten Daten stimmen am besten mit der Formel $\mathrm{C}^{19} \mathrm{H}^{26} \mathrm{O}^{10}$ ïberein. Letztere kann jedoch nur als eine vorläufige betrachtet werden, da die geringe Menge des mir zu Gebote stehenden Materials eine weitere Charakterisirung dieser Verbindung bisher nicht gestattete. $\mathrm{Ob}$ dieser von mir als $\mathrm{Cocculin}$ bezeichnete Körper identisch ist mit der von Barth in den Kokkelskörnern aufgefundenen, säureartigen Verbindung $\mathrm{C}^{9} \mathrm{H}^{12} \mathrm{O}^{5}$, oder mit dem Anamirtin von Barth und Kretschy, muss ich dahingestellt sein lassen. Der Umstand jedoch, dass jene Forscher das Anamirtin aus den Mutterlaugen von der fractionirten Krystallisation des Pikrotoxins aus Wasser abschieden, scheint nicht gerade für eine Identität von Cocculin und Anamirtin zu sprechen.

Conc. Schwefelsäure färbt das Cocculin nur schwach gelb; beim Reiben mit einem Glasstabe verschwindet die Fürbung wieder. Die Langley'sche Salpeterreaction, welche das Pikrotoxin und besonders das Pikrotoxinin scharf kennzeichnet, liefert das Cocculin nicht. 